\title{
Efficient Transdermal Penetration and Improved Stability of L-Ascorbic Acid Encapsulated in an Inorganic Nanocapsule
}

\author{
Jae-Hun Yang, Sun-Young Lee, Yang-Su Han, Kyoung-Chan Park, $+\underset{+}{+}$ and Jin-Ho Choỵ \\ National Kanohybrid Materials Laboratory, School of Chemistry \& Molecular Engineering, \\ Seoul Natonal Liniversity, Seon 151-7+7, Norea

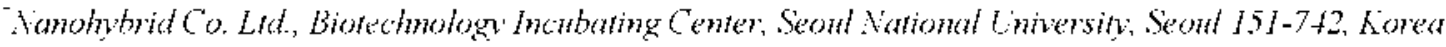 \\ Depament of Dennatolog, College of Medicine, Seoul National Liniversity, Seoul $110-7+4$, Korea \\ Received December 30,2002
}

\begin{abstract}
Fencapsulation ol' I-ascorbic acid (vitamin C) within a hio-compatible layered inorganie material was achieved by coprecipitation reaction, in which the lavered inorganie lattice and its interealate of vitamin $C$ are simultameously fomed. The nane-meter sired powders of vitamin $\mathrm{C}$ intercalate thus prepared was again tncapsulated with silica nano-sel to lom a nanoporous shell structure. This temary nanohy brid of vitamin Clay tred inorganic core-SiO, shell exhihiled an enhanced storage stability and a sustained releasing of vitamin C. Furthemos, the nano-encapsulation of vitamin $\mathrm{C}$ with inorganic mineral was very helpful in delivering vitamin $\mathrm{C}^{\mathrm{m}}$ molecules into skin through stratun comeum, lacilitating transdermal penctration of vitamin $\mathrm{C}$ in topical application.
\end{abstract}

Key Words : Layered inorganic material, L- $\Lambda$ scorbic acid, Encapsulation, Intercalation, Iransdermal penetration

\section{Introduction}

L-Ascorbic acid (vitamin C). a representative water soluble vitamin. las a variety of biological. plarmaccutical and dernatological functions: it promotes collagen biosynthesis. provides photoprotection. causes melanin reduction. scavenges free radical. and cnlances the immunity (anti-y irus effect). etc. ${ }^{\text {-1 }}$ These functions are closely related to the well-known antioxidant propertics of this compound. Vitamin $C$. however. is very unstable to air. moisture. light. heat. metal ions. oxygen. and base. and it casily decomposes into biologically inaciice compounds such as 2.3-dikclo-Lgulonic acid. oxalic acid. L-Ilurconic acid. L-xylonic acid. and L-Lyxonic acid. ${ }^{3}$ Therefore. the applications of vitamin $\mathrm{C}$ in the fields of cosmetics. dermatologicals. and phannaccuticals are limited despite of its useful functions. Thus to overcome chemical instability of vilamin C. cxtensive studies have been tricd on encapsulation and immobilization of vitamin $\mathrm{C}^{1.15}$ by using liposome. microcmulsions (watcrint-oil or oil in water). and liquid crystals. Anolher way of suppressing its decomposition is to derivatize the vitamin $\mathrm{C}$ as a salt such as ascorbyl palmitate or magnesium ascorbyl phosplate. Howerer. the instability problem of vitamin $\mathrm{C}$ still remains unsolved in cosmelic. dennatological and phannaccutical applications. More recently wo found that unstable biological and drug molecules sucl as DNA (dcoxyribonucleic acid). As-myc (c-myc antisense oligonuclcolide). ATP (adcnosin-5'-1riphospliatc). MTX (methotrexatc) can be remarkably stabiliyed and be effectively penctrated through various eell membranes when they were encapsulated in the layered inorganic matrix. ${ }^{11-1 \cdot t}$

"The author to whom correspondence should be addressed. Tel: +822-880-6658: Fax:+82-2-872-9864: Li-mail: ihchovi $\mathrm{plaza}$.snu.ac. $\mathrm{kr}$
In the present study: we are also very successful in demonstrating a new method of cncapsulating and stabilizing the vitamin $C$ in an inorganic layered materials like hydrated layered metal oxide with high biocompatibility and skin affinity. so that it can be applicable as the cosmetic ingredient. Here. we describe. For the first time. a novel ternary cncapsulation system in detail and discuss its physico-chemical propertics along with its clicmical stability. controlled relcase belavior. biological activity. and transdermal delivery elliciency.

\section{Experimental Section}

Synthesis. The cncapsulation of vitamin $\mathrm{C}$ with inorganic layer was achicicd by a chemical coprccipitation in an aqueous solution. ${ }^{15}$ Hydrated zinc oxide. $\mathrm{ZnO} \times \mathrm{x}_{2} \mathrm{O}$. was used as an inorganic matrix since it has positive surface charge. and it can thus immobilize anionic L-ascorbate specics. In a typical reaction. $\mathrm{Zn}\left(\mathrm{NO}_{3}\right)=6 \mathrm{H}_{2} \mathrm{O}(15.5 \mathrm{~g} .0 .05$ mol) was dissolycd in a decarbonated water $(300 \mathrm{~mL})$. and the aqucous metal solution was added into a solution containing L-ascorbic acid ( 0.1 M. $200 \mathrm{~mL}$ ). Then the pH of the reaction solution was adjusted to $6.7( \pm 0.2)$ by the addition of $\mathrm{NaOH}$ aqueous solution (0.1 M) under vigorous stirring. During the cncapsulation process. nitrogen gas was flowed through the reaction solution continuously to minimize the decomposition of L-ascorbic acid and to prevent the contamination from air. The white precipitate formed by coprecipitation reaction was aged at room temperature for 12 lirs. filtered. and washed witl decarbonated water thoroughly. Thus prepared core-slicll particle of vitamin C-liydrated xinc oxide hybrid was cncapsulated again with nano-sized silica ( $\mathrm{SiO}_{2}$ ) particles through the controlled tyydrolysis of tetracthy.lorthosilicate (TEOS. Si( $\left(\mathrm{OC}_{2} \mathrm{H}_{5}\right)_{4}$ ). In this second 
encapsulation process. $10 \mathrm{~g}$ of the vitamin C-lydrated zinc oxide hybrid gel was firstly re-dispersed in $35 \mathrm{~mL}$ ethanol and $10 \mathrm{~g}$ of TEOS was added slowly into the suspension. After $\mathrm{l}$ hr stirring. $15 \mathrm{~mL}$ decarbonated water was added to the suspension to induce the lydrolysis of TEOS, which was lasted for $2+$ hrs under continuous stirring. The resulting product was washed with ethanol thoroughly and dried under vacuum to form vitamin $\mathrm{C}$-inorganic $\left(\mathrm{ZnO}_{11} \mathrm{SiO}_{2}\right)$ ly brid particles (Vitabrid-C).

Chracterization. Powder X-ray diffraction patterns (XRD) were obtained with a Philips PW 3710 diffractometer with Ni-filtered $\mathrm{Cu}-\mathrm{K} \alpha$ radiation $(\lambda=1.5+18 \mathrm{~A}$ ) for the samples spread on slide glass. UV-ris spectra were obtained on a Perkin-Elmer Lambda 35 spectrophotometer to determine the content of L-ascorbic acid. Prior to the measurement, all the powdery samples were dissolved in $0.1 \mathrm{M} \mathrm{HCl}$ aqueous solution to recover pure L-ascorbic acid molecules encapsulated. Then the supernatant was analyzed after the filtration through a $0.2 \mu \mathrm{m}$ nylon filter using an absorbance maximum of $\lambda_{\text {tax }}$ at $245 \mathrm{~nm}$. corresponding to the typical absorption peak of L-ascorbic acid in acidic solution. High performance liquid clromatograply (HPLC) spectra were recorded on an Agilent 1100 Series Instrument equipped with UV detector $\left(\lambda_{\text {tlax }}=245\right.$ rum in acidic solution). An octadecyl-silica reversed-phase column $(4.6 \mathrm{~mm} \times 250 \mathrm{~mm}$. Zorbax), a mobile phase containing $0.15 \mathrm{mM}$ EDTA (ethylenediamintetracetic acid) and $25 \mathrm{~mL}$ potassium dihydrogen phosphate $\left(\mathrm{KH}_{2} \mathrm{PO}_{1}\right)$ with the $\mathrm{pH}$ of 2.5 , a flow-rate of $1 \mathrm{~mL} /$ min and $20 \mu \mathrm{L}$ of injection volume were used. Field emissionscanuing electron microscopic (FE-SEM) observation for Vitabrid-C was performed using a Hitachi $\mathrm{S}-4300$. Prior to the observation. the powder sample was coated with Pt-Pd for $150 \mathrm{~s}$ in racumm.

Controlled realeasing test. Time controlled releasing behavior of the encapsulated vitamin $\mathrm{C}$ in the core-shell particle was profiled in a $0.08 \% \mathrm{NaCl}$ aqueous solution. At first. Vitabrid-C powder ( $100 \mathrm{mg}$ ) was dispersed in $50 \mathrm{~mL}$ $0.08 \% \mathrm{NaCl}$ solution and stirred at $25^{\circ} \mathrm{C}$ with a rate of 50 rpm. The released amount of vitamin $C$ was determined periodically with UV-vis spectrum using the absorption peak at $265 \mathrm{~mm}$ ( $\lambda_{\text {m)ax }}$ of L-ascorbic acid in neutral solution).

Stability test. The stability of pure vitamin $C$ in Vitabrid-C powder in an aqueous solution was evaluated by monitoring the retention of vitamin $\mathrm{C}$ at the different storage periods. For the evaluation. $400 \mathrm{mg}$ of Vitabrid-C powder (containing $100 \mathrm{mg}$ of vitamin C) and $100 \mathrm{mg}$ of pure vitamin $\mathrm{C}$ (sodium L-ascorbate. as a reference) were separately added into the vials containing $10 \mathrm{~mL}$ of decarbonated water and sealed carefilly with the caps, and stored in an oven with the constant temperature of $42^{\circ} \mathrm{C}$. The content of vitamin $\mathrm{C}$ was analyzed periodically with HPLC.

In vitro L-DOPA oxidase inhibition test. L-DOPA oxidase inhibition activity was determined by a conventional method after minor modifications. ${ }^{16-19}$ The $0.1 \mathrm{M}$ phosphate buffer solution (PBS) of $\mathrm{pH} 6.8 .+\mathrm{mM}$ L-DOPA $(\beta-(3.4-$ dihydroxylphenyl)-L-alanine) and aqueous suspension of Vitabrid-C powder with the solid content of 0.1 .1 .10 . and
$100 \mathrm{ug} / \mathrm{nL}$ were prepared in advance. The aqueous solutions of L-ascorbic acid (pure vitamin C) with the content of (0.1. 1. 10 , and $100 \mu \mathrm{g} / \mathrm{mL}$ were also prepared as the reference in the L-DOPA oxidase inlubition tests. All the solutions and suspensions were stored in ice bath before the test. Each suspension (Vitabrid-C) and solution (pure vitamin C) for the test was added into $135 \mu \mathrm{L}$ PBS and gently mixed for 5 minutes. Then $20 \mu \mathrm{L}$ of $50 \mu \mathrm{g} / \mathrm{mL}$ tyrosinase was added into the solutions. followed by the addition of $40 \mu \mathrm{L}$ of $4 \mathrm{mM} \mathrm{L}$ DOPA to start the enzymatic reaction of L-DOPA to dopachrome at $37^{\circ} \mathrm{C}$ for 10 minutes. Then the absorbance at $475 \mathrm{~nm}$ of dopachrome was measured. L-DOPA oxidase inhibition value was exaluated by the following equation:

L-DOPA oxidasc inhibition $(\%)=[1-\{(\mathrm{B}-\mathrm{A}) /(\mathrm{D}-\mathrm{C})\}] \times 100$ $\mathrm{A} \& \mathrm{~B}$ : absorbances of the sample before and after the reaction $\mathrm{C} \& \mathrm{D}$ : absorbances of the blanks before and afier the reaction

DPPH assay. The free radical scavenging activity of Vitabrid-C and pure vitamin $C$ was evaluated by the previously reported method after minor modifications. The free radical scavenging activity of Vitabrid-C and Lascorbic acid was assayed using a relatively stable free radical. DPPH (2.2-diphenyl-1-(2.4.6-triuitrophenyl)hydrażl). $70 \%$ ethanol, $0.15 \mathrm{mM}$ DPPH solution, aqueous suspensions of Vitabrid-C powder with the solid content of $0.1 .1,10$. and $100 \mu \mathrm{g} / \mathrm{mL}$, and pure vitamin $\mathrm{C}$ solutions of 0.1 . 1. 10. and $100 \mu \mathrm{g} / \mathrm{mL}$ were stored in an ice bath, respectively. $5 \mu \mathrm{L}$ of the test samples (Vitabrid-C suspensions or pure vitamin $\mathrm{C}$ solutions) were added into $115 \mu \mathrm{L}$ of $70 \%$ ethanol. separately: After mixing the solution homogeneously. $80 \mu \mathrm{L}$ of 0.15 $\mathrm{mM}$ DPPH solution was added into the solutions. respectively: Then the redox reaction was carried out at room temperature for 20 minutes, and the free radical scavenging activity of each antioxidant was quantified by comparing the change of absorbance at $517 \mathrm{~lm}$. Radical scavenging activity was evaluated by the following equation:

Radical scavenging aclivity $(\%)=[1-\{(\mathrm{B}-\mathrm{A}) /(\mathrm{D}-\mathrm{C})\}\rceil \times 100$ $\mathrm{A} \& \mathrm{~B}$ : absorbance of the samples before and after the reaction $\mathrm{C} \& \mathrm{D}$ : absorbance of the blanks before and after the reacion

Transdermal transfer test. The passive permeability of vitamin $\mathrm{C}$ in Vitabrid-C powder. $w / 0$ emulsion containing Vitabrid-C and o/w emulsion containing L-ascorbic acid was inrestigated by Franz diffusion cell method ${ }^{23-2.5}$ using hairless mouse skin with an effective diffissional area of $0.6+\mathrm{cm}^{2}$. The skin samples were hydrated in advance in PBS for 15 minutes before setting them to the chambers. Receiver compartment vehicle consisted of $5.2 \mathrm{~mL}$ of $0.0001 \%$ dithiothreitol (DTT). $0.00042 \%$ EDTA. and $25 \mathrm{mM}$ potassium dihydrogen phosphate buffer solution $(\mathrm{pH}+.5)$. $0.04 \mathrm{~g}$ of Vitabrid-C powder and $1 \mathrm{~g}$ of emulsion samples were added into each donor compartment, respectively, and sealed with parafilm to prevent evaporation. In case of Vitabrid-C powder, a few drops of $0.8 \mathrm{wt} \% \mathrm{NaCl}$ aqueous solution was added into the donor compartment to wet the powder sample, thus to mimic an artificial sweat condition on human skin. Permeated L-ascorbic acid was withdrawn from receiver 
(100 $\mu \mathrm{L}$ ) chambers penodically and analyzed by HPLC. And then the same volume of pure velucle was added to the recerver to maintain a constant volume.

\section{Results and Discussion}

The encapsulation of L-ascorbic acid with morganc layer was achiered by chemical coprecipitation in an aqueous solution. L-ascorbic acid is a weak acid $\left(\mathrm{pK}_{1}=4.17\right){ }^{l}$ and it becomes deprotonated in aqueous solution at the $\mathrm{pH}>4.17$ to form an anonic L-ascorbate species. Since the hydrated zinc oxide has a positive surface charge. the anionic ascorbate molecules would be adsorbed onto the inorganuc surface during coprecipitation. leading to the encapsulation of vitamin $\mathrm{C}$ molecule in the inorganic layers.

Figure 1 shows the $X$-ray diffraction patterns of the vitamin C- lydrated zinc oxide lyybrid obtained during the first encapsulation process (a) and the silica modified one (Vitabrid-C) (b). As can be seen from Figure l(a). primary L-ascorbic acid-inorganic hybrid shows a layer character with the basal spacing of $14.5 \mathrm{~A}$. This suggests that Lascorbate anions are inserted between the zinc hydroxide sheets to form an intercalate with $1: 1$ layer sequence along the c-axis where L-ascorbate molecules are encapsulated by inorganc layers as depicted in the inset. Upon encapsulation of the L-ascorbic acid-inorganic hybrid within the shell of nano-sized silica particles. the crystalline phase disappears as shown in XRD (b). suggesting that the silica deposition on the primary $\mathrm{L}$-ascorbic acid-inorganic hybrid gives rise to a drastic suppression of long range ordering. According to the elemental analysis and vitamin $C$ content, the primary lybrid was found to be composed of $49.0 \mathrm{wt} \% \mathrm{ZnO}_{-} .42 .1$ $w \%$ vitamin $\mathrm{C}$. and $8.9 \mathrm{wt} \% \mathrm{H}_{2} \mathrm{O}$. On the other hand, the silica coating on the hybrid led to a change in composition with $40.7 \mathrm{wt} \% \mathrm{SiO}_{2} .29 .0 \mathrm{wt} \% \mathrm{ZnO} .25 .0 \mathrm{wt} \%$ vitamin $\mathrm{C}$. and $5.3 \mathrm{wt} \% \mathrm{H}_{2} \mathrm{O}$.

Figure 2 represents the scanning electron micrograph (SEM) image of Vitabrid-C powders, which consist of spherical aggregates with a homogeneous particle size of

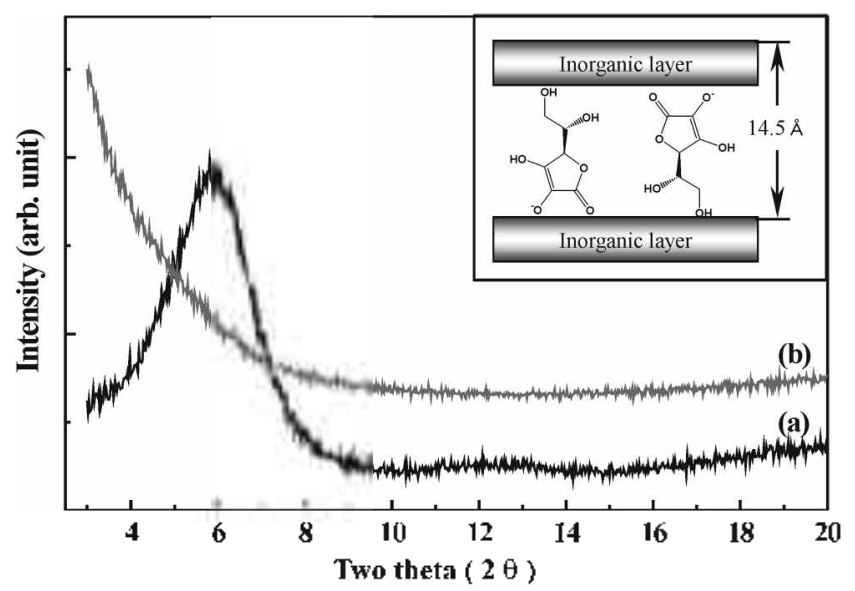

Figure 1. Powder X-ray diflrastion pallems of (a) vitamin $\mathrm{C}$ hỵdraled cinc oxide nanohybrid and (b) Vitabrid-c, respectively.

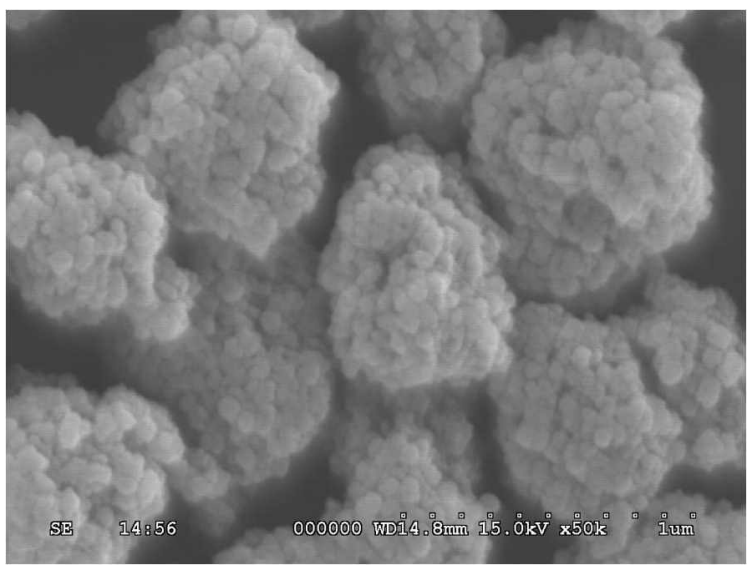

Figure 2. Scanning electron micororaph of Vitabrid-C. powder.

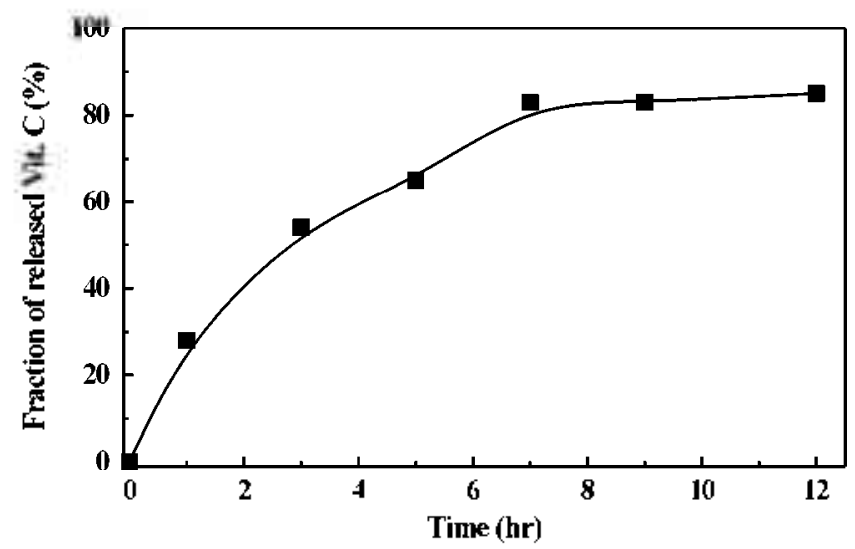

Figure 3. lime controlled releasing curve of vitamin $C^{\prime}$ in Vilabrid-C pouticr.

$-0.5 \mu \mathrm{m}$ and size distribution. In addition. one can see clearly nano-sized silica particles to form nanoporous shell structure.

The controlled release of vitamin $C$ from Vitabrid-C powder could be demonstrated as shown in Figure 3. The vitamin $\mathrm{C}$ molecules encapsulated in the interlayer space of morganuc layers are replaced gradually by foreign chloride anions via ion-exchange process in an aqueous solution of

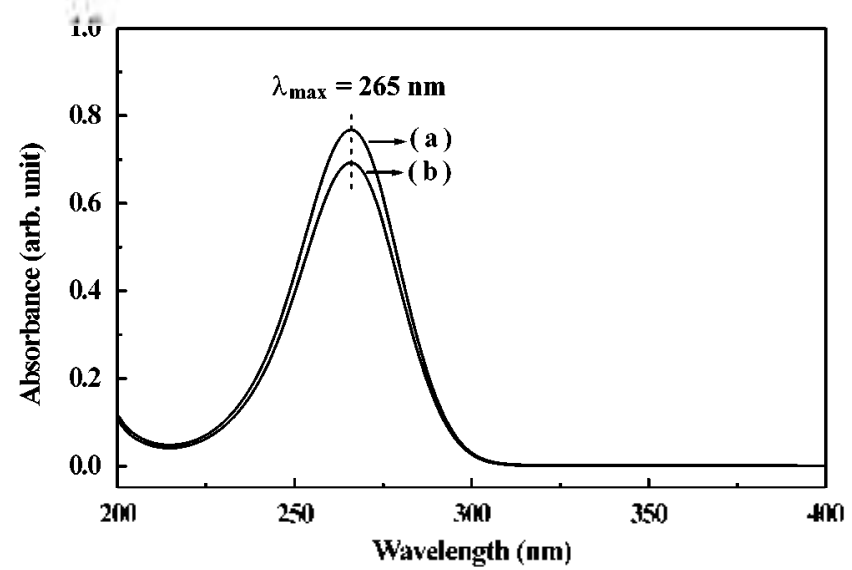

Figure 4. UV-vis spectra of (a) relcasol vitamin C from Vitabrid-C and (b) purc vitamin C (sodium L-ascorbate). 


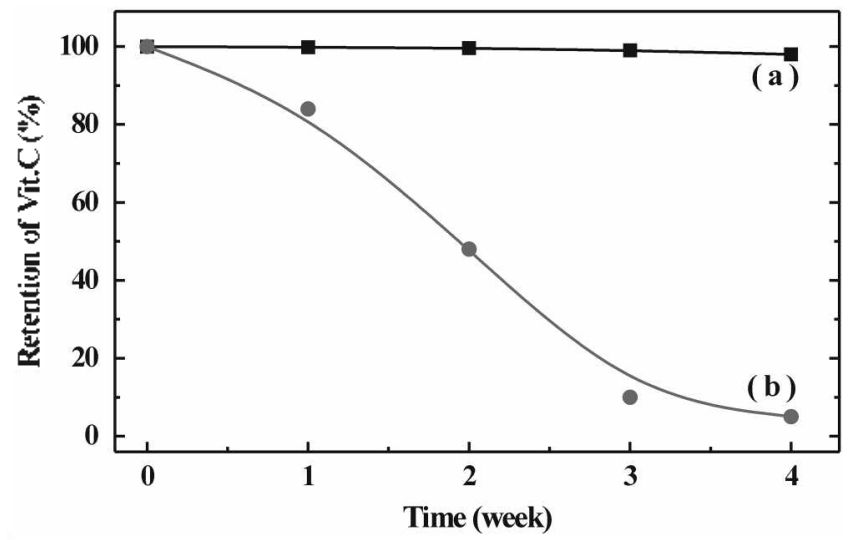

Figure 5. Retention of vitamin $C$ in (a) Vitabrid-C and (b) pure vitamin $\mathrm{C}$ ( sodium $\mathrm{I}$-ascorbate) at $42{ }^{\circ} \mathrm{C}$. in acpueous medium.

$0.08 \% \mathrm{NaCl}$ and released in a time-controlled manner. The released vitamin $\mathrm{C}$ is comfimmed to be the pure one by comparing the UV-vis specta for both, since they show the same absorption maximum (Fig. 4).

Figure 5 compares the retention stability of pure vitamin $C$ and Vitabrid-C powder in an aqueous solution at $+2{ }^{\circ} \mathrm{C}$. The active vitamin $\mathrm{C}$ content in an aqueous solution of pure vitamin $C$ decreases rapidly and down to $<10 \%$ within + weeks. While the vitamin $\mathrm{C}$ molecules in Vitabrid-C remain almost constant up to 4 weeks. More than $95 \%$ of vitamin C molecules are retained in this lybrid system after + weeks. Such an excellent stabilization of vitamin $C$ is mainly due to the encapsulation of vitamin $C$ molecules with inorganic nano-layer on a molecular level through the interfacial surface charge interaction between L-ascorbate and inorganic zinc lydroxide layers.

The results of L-DOPA oxidase inhibition activity test and radical scarenging activity one (DPPH assay) for Vitabrid-C and pure vitamin $\mathrm{C}$ are summarized in Table $\mathrm{l}$. According to the L-DOPA oxidase inhibition activity test. Vitabrid-C shows the inhibition activity equivalent to pure vitamin $C$. Vitabrid-C has the activities of $46.8 \%$ and $99.7 \%$ when the Vitabrid-C contents are $10 \mu \mathrm{g} / \mathrm{mL}$ and $100 \mu \mathrm{g} / \mathrm{mL}$. respectively: The value of $\mathrm{ID}_{\text {ii }}$ a critical concentration of sample required to reduce the L-DOPA oxidase activity to $50 \%$. of Vitabrid-C is determined to be $15.4 \mu \mathrm{g} / \mathrm{mL}$ which is very close to the ID ${ }_{5 i}$ value for pure vitamin $C$ of $16.9 \mu \mathrm{g} /$ $\mathrm{mL}$. Therefore. it is evident that the vitamin $C$ encapsulated by inorganic matrix has a biological activity equivalent to pure vitamin $C$.

The antioxidant potentials of Vitabrid-C and pure vitamin $C$ were also exaluated by measuring the DPPH radical concentration. and found to be the same irrespective of the concentration. indicating that Vitabrid- $\mathrm{C}$ could play an effective role as the radical scavenger. From the L-DOPA oxidase inhibition and DPPH tests, it is concluded that vitamin $\mathrm{C}$ molecules are encapsulated sifely by inorganic materials without loss of their biological activity.

The profiles of transdemal transport of sitamin $\mathrm{C}$ in Vitabrid-C powder (a). Vitabrid-C-containing w/o emulsion (b). and pure vitamin $\mathrm{C}$-containing o/w emulsion (c) are

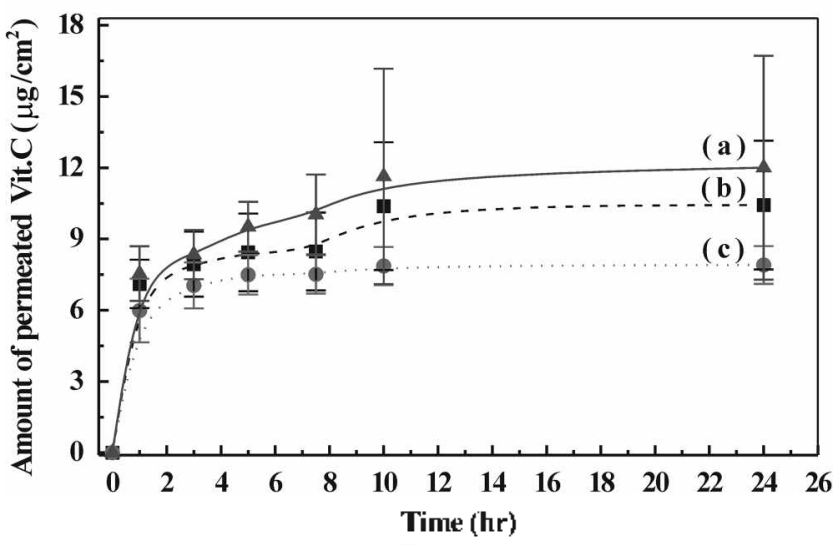

Figure 6, Skin permeation proliles of vitamin $(\mathrm{C}$ in (a) Vitabrid-C powder; (b) Vitabrid-C-containing wo emusion, and (c) pure vitamin $\mathrm{C}$-containing o/w emulsion, respectively.

Table 1. DOPA oxidase inhibition activity and tadical scavenging activity of Vitabrid-C and pure vitamin C

\begin{tabular}{|c|c|c|c|c|}
\hline \multirow{2}{*}{ Concentration } & \multicolumn{2}{|c|}{$\begin{array}{c}\text { 1,-1)OPA Oxidase Activity } \\
\left({ }_{(0}^{\circ}{ }_{0}\right)\end{array}$} & \multicolumn{2}{|c|}{ DPPH Test $\left({ }^{0} 0\right)$} \\
\hline & $\begin{array}{l}\text { Pure vilamin C. } \\
\text { (Relerence) }\end{array}$ & $\begin{array}{c}\text { Vitabrid } \\
\text {-C }\end{array}$ & $\begin{array}{l}\text { Pure vitamin C } \\
\text { (Relerence) }\end{array}$ & $\begin{array}{l}\text { Vitabrid } \\
-C\end{array}$ \\
\hline $0.1 \mu \mathrm{g} \mathrm{ml}$ & 9.9 & 8.7 & 2.6 & 0.8 \\
\hline $\mathrm{l} \mu \mathrm{g} \mathrm{ml}$ & 20.5 & 22.9 & 11.2 & 11.5 \\
\hline $\mathrm{l} 0 \mathrm{\mu g} \mathrm{ml}$ & 45.8 & 46.8 & 69.5 & 68.2 \\
\hline $\mathrm{l}(x) \mu \mathrm{g} \mathrm{ml}$. & 100 & 99.7 & 88.3 & 88.3 \\
\hline
\end{tabular}

shown in Figure 6. The cumulative amount of vitamin C pemeated though the skin is expressed per $\mathrm{cm}^{2}$ in the graph. The overall features of permeation patterns are quite simular one another. suggesting the similar penetration mechanism irrespective of the sample forms. However. the absolute amounts of permeated vitamin $\mathrm{C}$ after $2+$ hrs are more or less different with the following order: Vitabrid-C powder $\left(12.0 \mu \mathrm{g} / \mathrm{cm}^{2}\right)>$ Vitabrid-C-containing w/o emulsion $(10.4$ $\left.\mu \mathrm{g} / \mathrm{cm}^{2}\right)>$ pure vitamin C-containing o/w emulsion $(7.9 \mu \mathrm{g} /$ $\left.\mathrm{cm}^{2}\right)$. This indicates clearly that the inorganically encapsulated vitamin $C$ shows higher penetration rate than the pure vitamin $C$. Though the delivery mechanism should be further studied. it becomes evident that the encapsulation of vitamin $C$ in an inorganic nano-capsule and its controlled release behavior are important factors for the effective penetration of vitamin $\mathrm{C}$ molecules through the skin barrier.

The proposed releasing and delivering mechanism of vitamin $\mathrm{C}$ molecules in Vitabrid-C is schematically represented in Figure 7. In Vitabrid- $C$. the vitamin $C$ molecules are adsorbed and immobilized between inorganic lavers with positive surface charge. and further coated with nano-sized silica particles, forming a nanoporous shell structure. Due to its well developed nanoporous structure. the Vitabrid-C absorbs effectively the skin wastes. sebums, and sweats discharged from the human skin. Actually: the Vitabrid-C shows a large oil adsorption capacity more than $150 \%{ }^{-6}$ The absorption of chemical species such as $\mathrm{NaCl}$ and fatty acids in sweat and skin wastes into the nanopores of Vitabrid-C 


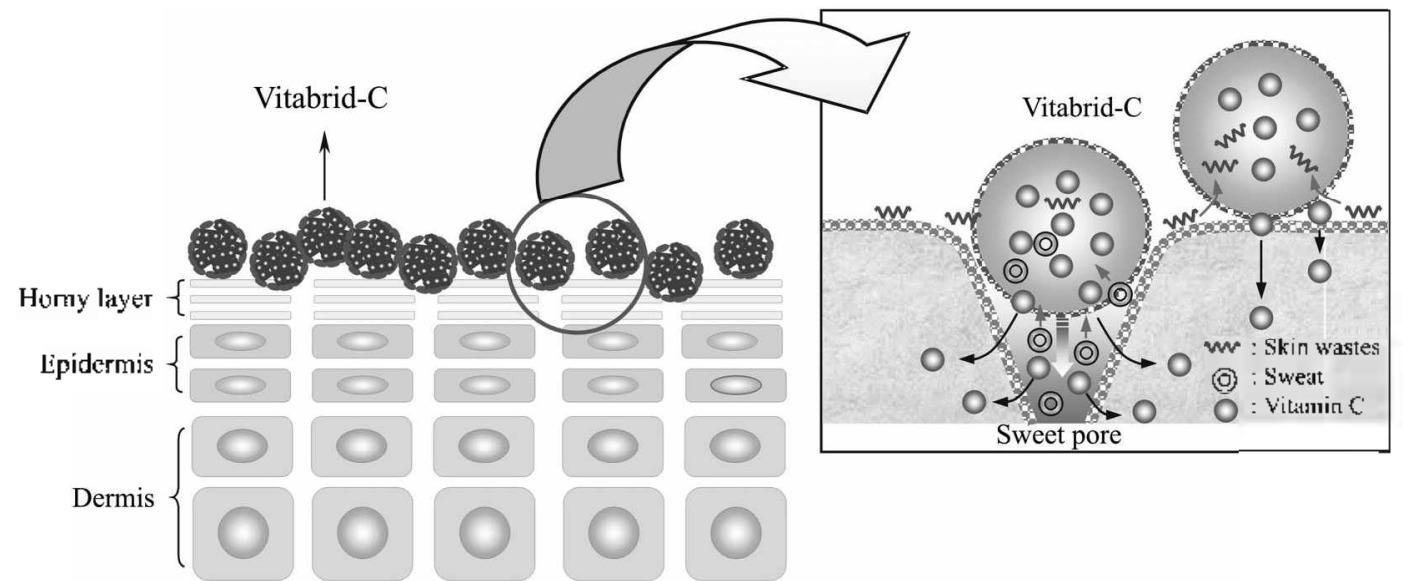

Figure 7. The proposed releasing and delivering mechanism of vitamin $\mathrm{C}$ in Vitabrid-C.

gives rise to a release of vitamin $C$ in the pore by the exchange reaction between them. in such a way the vitamin C molecules could be slowly diffused out from the inorganic shell and delivered into the epidermis in skin.

\section{Conclusion}

L-Ascorbic acid molecules with various biological. pharmaceutical and dermatological functions are encapsulated and immobilized successfully with bio-compatible and skinfriendly inorganic materials by wet chemical method. The encapsulated vitamin C (Vitabrid-C) shows a superior storage stability in aqueous medium compared to the pure sodium Lascorbate. and an excellent time-controlled releasing behavior. Furthermore the Vitabrid-C has a biological activity (LDOPA oxidase inlubition and free radical scavenging activity) equivalent to the pure L-ascorbic acid. It is, therefore. quite evident that the reversible inclusion and the time controlled release properties of vitamin $C$ stabilized in Vitabrid-C are important factors for allowing the vitamin $\mathrm{C}$ molecules to penetrate the skin barrier effectively thanks to the nanosized inorganic deliven carrier.

Acknow ledgments. This work was supported by a grant of the Korea Health 21 R\&D Project (02-PJl-PGl-CHll$0001)$, the Korean Ministry of Health and Welfare. Authors are grateful for the BK21 program.

\section{References}

1. Machlin. L. J. Hondbook of Litamins. 2nd Ed.: Marcel Dekker. Inc: 1991

2. Doba, T.: Burton, G. W.: Ingold. K. U. Biochim Biophns . Acto $1985,835,298$

3. Bossi. A.: l'iletsky. S. A.: l'iletska. E. V.: Righelli. P. G.: Tumer. A. l'. F. .that Chem. 2000. 72. 4296.
4. Yamamoto. 1.: Tai. A.: Fujinami. Y.: Sasaki. K.: Okatzaki. S. $J$. Med Chem 2002. 45,462 .

5. Tsuchiva, II.: Bates, C. I. J. Nint. Biochem 1998. 9. 402.

6. IIorino, Y.: Takahashi. S.: Miura. T.: Takahashi, Y. fife Scieffee 2002. 71. 3031 .

7. Gallarate. M.: Carloti. M. E.: Trotta. M.: Bowo. S. Int. J. Ihamm. 1999. 188. 233

8. Austria, R.: Semenzato. A.: Bettero. A. J. Pharm. Biomed inal. 1997, 15. 795 .

9. Spriclin, P. Gasperlin, M.: Knetec. V. Int. J. Pham. 2001, 222. 271 .

10. Semenzalo. A.: Austria. R.: DallAglio. C.: Bettero. A. $J$. Chomatogr if 1995. 705. 385 .

11. Choy. J. II.: Kwak. S. Y.: Park. J. S.: Jeong. Y. I. Angew! Chem. Int Fd. 2000, $39(22), 4042$.

12. Chon. I. II.: Kwak, S. Y.: Park. J. S.: Jeong. Y. I.: Porticr, J. J. . Im. Chem. Soc 1999. 121. 1399.

13. Choy. J. H.: Kwak. S. Y.: Park. J. S.: Jeoner. Y. J. J. Mater Chem. 2001. $/ 1(6) .1671$.

14. Choy: J. II.: Park, I. S.: Kwak. S. Y.: Icong. Y. J.: I Ian. Y. S. M Iol (inst d. Itiq. (rist. 2000, 3H1, 425 .

15. IIwang. S. H.: Han. Y. S.; Chos: I. H. Bull. Sorem Chem. Soc. 2001. 22. 1019

16. Riley. P'. A. Cell. Lot Biol 1999. 45.951.

17. Han. W. S.: Yoo. J. Y.: Youn. S. W.: Kim. D. S.: Park. K. C.: Kim. S. Y. Kim. K. I. J. Dermatol. Sci. 2002. 30.10.

18. Kubo, I.: Kinst-I Iori. I. J. Igric. Food Chem 1999. +7. +121 .

19. Jimenez, M.: Chazarra. S.: Ferribano, I.: Cabancs. J.: GarciaCarmona. F. J. Agric. Food C $/ \mathrm{km}$ 2001. 49. 4060.

20. Iachibana. Y.: Kikuzaki. H.: Lajis. N. H.: Nakatani. N. J. Agric. Food $C h$ im. 2001. t9. 5589 .

21. Kim, D. O.: J.ec. K. W.: I.ee, II. I.: I.ce, C. Y. . Igric. Food (7) 2002. 50.371 .3 .

22. Sawa, Y.: Moon. J. II. J. Igric. Food ( $/ k^{\prime} m$. 2000, $48,6247$.

23. Simonsen. L.: P'elersen. M. B.: Groth. L. Ew J. Pham Sci. 2002. 17.95.

24. Wissing. S. A.: Muller. R. H. J. Control. Release 2002. 81. 225

25. Youenang Picmi, M. P.: De T.uca, M.: Grossiord, J. I.: Sciller, M.: Marty, I. P. Int. J. Fham 1998, 17/. 207

26. Oil adsorption capacity was measured by KS (Korean Industrial Standard) method. 